\title{
The effects of climate change on avian diversity in high altitude wetland habitats
}

\begin{abstract}
Birds are a major component of wetland ecosystems and often exhibit a distinct correlationship with wetland vegetation and food resources. Conversely, long-term effects of the climate change on avian community parameters and their habitats have not been examined in high-altitude wetland habitats. However these wetlands are highly important for a variety of avian species, i.e., they utilize the high-altitude wetland habitats permanently or in transit (i.e., stopover) during migration from September to March. Climate change is a major driving factor that affects avian diversity through various ways such as altered microclimate factors (temperature, relative humidity, and rainfall pattern) and microhabitat characteristics that had caused a shift in home range, food resources, and breeding ecology of various bird species inhabiting high-altitude wetland habitats. The current chapter indicates that climate change affects phenology, distribution, migration season (i.e., arrival and departure), and breeding ecology of avian species. In fact, very little is known about the effects of the climate change on the avian diversity in high-altitude wetland habitats. Hence, it is crucially important to determine the effects of climate change on avian diversity in highaltitude wetland habitats within the context of ecological and spatial parameters to understand the effects of climate change on avian diversity and their habitat for future wetland habitat conservation and management.
\end{abstract}

Keyword: Avian diversity; High-altitude wetland habitats; Climate change; Waterbird 